
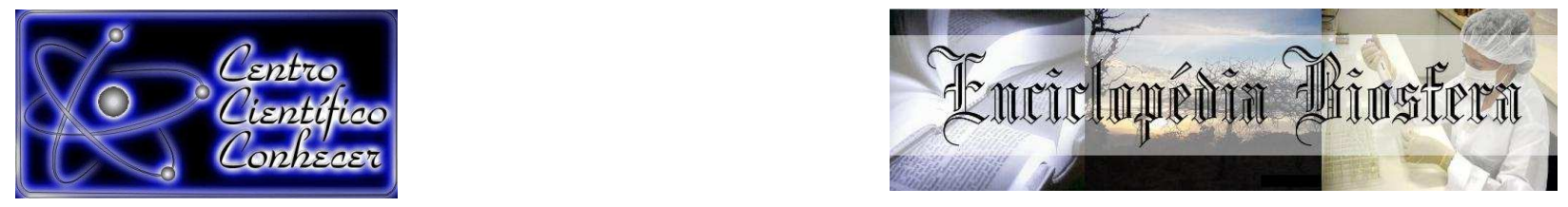

\title{
RETARDAMENTO DE COLHEITA NA QUALIDADE FISIOLÓGICA DE SEMENTES DE FEIJÃO
}

\author{
Raimunda Nonata Oliveira da Silva *1, Márcio Gonçalves da Silva ${ }^{1}$, Paulo Eduardo \\ Rocha Eberhardt ${ }^{2}$, Matheus Lemons e Silva ${ }^{3}$, Luis Eduardo Panozzo ${ }^{4}$ \\ ${ }^{1}$ Eng. Agrônomo (a), Mestrando (a) no PPG em Ciência e Tecnologia de Sementes, \\ Universidade Federal de Pelotas, Rio Grande do Sul - Brasil \\ ${ }^{2}$ Eng. Agrônomo (a), Doutorando (a) no PPG em Ciência e Tecnologia de Sementes, \\ Universidade Federal de Pelotas, Rio Grande do Sul - Brasil \\ ${ }^{3}$ Graduando em Agronomia, Faculdade de Agronomia Eliseu Maciel, Universidade \\ Federal de Pelotas, Rio Grande do Sul - Brasil \\ ${ }^{4}$ Professor orientador no PPG em Ciência e Tecnologia de Sementes, Universidade \\ Federal de Pelotas, Rio Grande do Sul - Brasil \\ *Autor correspondente - nonas_agro@hotmail.com
}

\section{Recebido em: 08/04/2016 - Aprovado em: 30/05/2016 - Publicado em: 20/06/2016 DOI: 10.18677/Enciclopedia_Biosfera_2016_105}

\begin{abstract}
RESUMO
Para alcançar a máxima qualidade das sementes, o momento ideal de colheita é de suma importância, no entanto, atrasos podem ocorrer, comprometendo assim, a qualidade das sementes devido à deterioração em campo. Objetivou-se avaliar a qualidade fisiológica de sementes de feijão em função do retardamento de colheita. O delineamento utilizado foi de blocos ao acaso em esquema fatorial $2 \times 3$, com quatro repetições. Os tratamentos constituíram-se de dois genótipos de feijão (Iraí e BRS Expedito) e três épocas de colheita (maturação de colheita, sete e 14 dias após maturação de colheita). As sementes provenientes das diferentes épocas de colheitas foram submetidas aos testes de germinação, comprimento radicular, massa de mil sementes, emergência a campo e índice de velocidade de emergência. $O$ retardamento de colheita de sementes de feijão até 14 dias após a maturidade de colheita promove perdas de qualidade fisiológica de sementes, entretanto as sementes poderiam ser comercializadas tendo em vista que apresentaram germinação igual ou superior a $80 \%$ em todas as situações de colheitas estudadas. Cultivares de feijão apresentam distintas tolerâncias à deterioração de sementes em campo devido ao retardamento de colheita.
\end{abstract}

PALAVRAS- CHAVE: Deterioração, Phaseolus vulgaris L., potencial fisiológico.

\section{HARVEST DELAY IN QUALITY PHYSIOLOGICAL BEAN SEEDS}

\begin{abstract}
To achieve the highest quality of seed, the ideal time to harvest is of paramount importance, however, delays can occur, thus jeopardizing the quality of seed due to deterioration in the field. Objective to evaluate the physiological quality of seeds depending on the bean harvest delay. The delineation used was random block in factorial scheme $2 \times 3$, with four replicates. The treatments had consisted of two bean genotypes (Iraí and BRS Expedito) and three seasons of harvest (harvest maturity, ENCICLOPÉDIA BIOSFERA, Centro Científico Conhecer - Goiânia, v.13 n.23; p.1203 2016
\end{abstract}


seven and 14 days after harvest maturity). The seeds from different epochs of crops were subjected to the tests of germination, root length, mass of 1000 seeds, emergency and emergency speed index. The harvest delay of bean seeds until 14 days after harvest maturity promotes loss of physiological quality of seeds, however the seeds could be marketed as presented germination $80 \%$ or more in all situations studied crops. Bean cultivars present different tolerances to deterioration of seed in the field due to harvest delay.

KEYWORDS: Deterioration, Phaseolus vulgaris L., physiological.

\section{INTRODUÇÃO}

A cultura do feijão comum (Phaseolus vulgaris L.) ocupa posição de destaque socioeconômico no cenário da agricultura brasileira, sendo utilizado, principalmente para o abastecimento do mercado interno. Trata-se de uma importante fonte de proteínas, aminoácidos, ácidos graxos e minerais na dieta da população brasileira (CARVALHO et al., 2014). Portanto, pesquisas e tecnologias devem ser desenvolvidas buscando o aumento da produção e produtividade desta fabácea, que no Brasil apresenta índices de produtividade bem abaixo do potencial dos genótipos disponíveis para o cultivo.

Atualmente, a média de produtividade nacional do feijoeiro é de aproximadamente $1.096 \mathrm{~kg} / \mathrm{ha}$ (CONAB, 2016), enquanto que o potencial da cultura pode ultrapassar $3.000 \mathrm{~kg} / \mathrm{ha}$ (PEREIRA et al., 2014). A utilização de sementes de elevada qualidade é essencial para elevar os índices de produtividade da cultura do feijão (MAMBRIN et al., 2015). Os efeitos da qualidade fisiológica de sementes no crescimento inicial de plantas, desempenho de plantas, uniformidade da lavoura, e inclusive na produtividade de grãos de feijão tem sido bastante estudado e comprovado em diversas culturas (KOLCHINSKI et al., 2006; MATTIONI et al., 2012; TAVARES et al., 2013; CANTARELLI, et al., 2015a; 2015b).

Um dos maiores entraves para o desenvolvimento da indústria de sementes de feijão no Brasil é a baixa taxa de utilização de sementes (MENTEN et al., 2006), para a cultura do feijão, na safra 13/14 correspondeu apenas a 19\% (ABRASEM, 2014). Este fato desestimula o setor sementeiro para investimentos em tecnologias de produção de sementes de feijão. Assim, a utilização de práticas de manejo e tecnologias é de extrema importância para obtenção de lotes de sementes de qualidade superior.

A colheita de sementes envolve a capacidade de gerenciar e de identificar o momento ideal da colheita, como também a disponibilidade de máquinas para retirar os materiais do campo o mais rápido possível sem afetar negativamente sua qualidade (PESKE, 2014). O momento ideal de colheita do feijão é no ponto de maturidade fisiológica, momento este, em que as sementes possuem elevado vigor e alta taxa de germinação. Porém, no ponto de maturidade fisiológica, o grau de umidade das sementes é muito alto para que se possa realizar a colheita e debulha, principalmente se esta for mecanizada, ao qual só poderá ocorrer quando as sementes atingirem o grau de umidade adequada (PESKE et al., 2012; MARCOS FILHO, 2015).

Entretanto, na indústria de sementes o momento de colheita dos campos de produção é bastante conturbado, devido a grande área a ser colhida e o frequente excesso de chuvas na ocasião da colheita, o que tem promovido atrasos na retirada das sementes do campo. O retardamento da colheita torna as sementes 
susceptíveis à deterioração e ataque de micro-organismos no campo, devido à interferência de fatores do meio ambiente, como temperatura, umidade relativa do ar e precipitações (MARCANDALLI et al., 2011; KAPPES et al., 2012). Podendo promover a redução da qualidade fisiológica de sementes produzidas e queda de produtividade devido à deiscência das vagens (BOTELHO et al., 2010). No entanto, faltam estudos para determinar quais são os períodos limítrofes para retardar a colheita sem ter perdas acentuadas na qualidade fisiológica das sementes.

Neste contexto, objetivou-se avaliar a qualidade fisiológica de sementes de feijão em função do retardamento da colheita.

\section{MATERIAL E MÉTODOS}

O delineamento experimental utilizado foi de blocos casualizados em esquema fatorial (2x3), sendo dois genótipos (Irai, BRS Expedito) e três épocas de colheita (maturação de colheita, sete e 14 dias após a maturação) com quatro repetições. BRS Expedito possui hábito de crescimento indeterminado, tipo II, enquanto Iraí é hábito de crescimento determinado, tipo I.

Cada bloco foi constituído por um canteiro com 14 linhas de um metro de comprimento, espaçadas em 0,35 $\mathrm{m}$ nas entre linhas, sendo que cada unidade experimental correspondeu a duas linhas centrais. Foram semeadas 25 sementes por linha e posteriormente realizou-se o desbaste mantendo-se 10 plantas por linha. Em cada extremidade dos canteiros foi semeada uma linha de bordadura.

Para o desenvolvimento das plantas e produção das sementes, foram utilizados canteiros de $6 \mathrm{~m}^{2}$ preenchidos com solo, classificado como planossolo háplico eutrófico solódico, pertencente à unidade de mapeamento de Pelotas-RS (EMBRAPA, 2006).

As plantas de cada tratamento foram colhidas manualmente da área útil das linhas, e depois de colhidas, as vagens foram destacadas das plantas e imediatamente colocadas para secar em estufa de ar forçado a $35^{\circ} \mathrm{C}$, até atingirem umidade de $12 \%$, para posterior debulha. No experimento foram avaliadas as seguintes variáveis para determinar a qualidade fisiológica das sementes: germinação (GER), comprimento radicular (CR), massa de mil sementes (MMS), emergência a campo (EC) e índice de velocidade de emergência (IVE).

O Teste de germinação (G) foi conduzido utilizando-se 200 sementes, subdividas em quatro rolos de 50 sementes por repetição. As sementes foram colocadas em papeis germitest umedecidos com água destilada equivalente a 2,5 a massa do papel seco e colocadas em germinador com temperatura a $25^{\circ} \mathrm{C}$. A avaliação foi realizada no oitavo dia após a semeadura, considerando a percentagem de plântulas normais, conforme as Regras para Análises de Sementes (RAS) (BRASIL, 2009).

O comprimento radicular $(\mathrm{CR})$ foi realizado na contagem final do teste de germinação. Foram utlizados 40 plântulas por repetição. As raízes foram medidas com o auxílio de uma régua graduada e os resultados foram expressos em centímetros (cm) (NAKAGAWA, 1999). Para a massa de mil sementes (MMS) foram utilizadas oito repetições de 100 sementes, conforme critérios estabelecidos pelas RAS (BRASIL, 2009).

Para o teste de emergência a campo (EC) utilizou-se 200 sementes, divididas em quatro repetições de 50 sementes, semeadas em canteiros com profundidade de aproximadamente quatro $\mathrm{cm}$. A contagem foi realizada 21 dias após a semeadura. 
Os dados foram submetidos a analise de normalidade e homocedasticidade. Após, contempladas as pressuposições, realizou-se a análise de variância $(p<0,05)$ e, quando significativas, as mesmas foram comparadas pelo teste de Tukey a $5 \%$ de probabilidade.

\section{RESULTADOS E DISCUSSÃO}

Para a variável germinação observou-se interação significativa entre os fatores estudados (cultivares e época de colheita) (Tabela 1). As diferentes épocas de colheitas não influenciaram negativamente a germinação do cultivar BRS Expedito, mostrando-se mais tolerante ao retardamento de colheita. Já a cultivar Iraí apresentou perdas de germinação na ordem de 15\% em relação a medias das outras duas épocas de colheita, como também, uma diferença de $20 \%$ na comparação com a cultivar BRS Expedito para a última colheita.

Pode-se observar que à medida que as sementes permanecem no campo após a maturidade fisiológica, o potencial de germinação tende a diminuir, em decorrência do processo de deterioração. Neste sentido, BRACCINI et al. (2003), observaram que a percentagem de germinação reduziu à medida que houve o retardamento de colheita, porém, esse comportamento foi diferente para as cultivares avaliadas. Em estudos realizados por LIMA et al. (2007) sobre o retardamento de colheita de sementes de soja, verificaram que a partir de 15 dias após a maturação de colheita, houve a diferenciação entre genótipo em relação a tolerância ao retardamento de colheita. Normalmente, a qualidade das sementes tende a diminuir a partir da maturidade fisiológica, dependendo das condições climáticas, principalmente em função da temperatura e da umidade relativa do ambiente em que estas ficam expostas, até o momento de serem colhidas (GARCIA et al., 2004).

TABELA 1. Valores médios de Germinação, comprimento radicular e massa de mil sementes de sementes de feijão colhidas em três épocas de colheitas.

\begin{tabular}{|c|c|c|c|c|c|}
\hline \multirow{2}{*}{$\begin{array}{l}\text { Variável } \\
\text { Resposta }\end{array}$} & \multirow{2}{*}{ Genótipo } & \multicolumn{3}{|c|}{ Época de Colheita } & \multirow{2}{*}{ Média } \\
\hline & & M.C & M.C. +7 dias & M.C. +14 dias & \\
\hline \multirow{4}{*}{$\begin{array}{c}\text { Germinação } \\
(\%)\end{array}$} & BRS Iraí & $95 \mathrm{Aa}$ & $93 \mathrm{Aa}$ & $80 \mathrm{Bb}$ & 89 \\
\hline & BRS Expedito & $98 \mathrm{Aa}$ & $99 \mathrm{Aa}$ & $98 \mathrm{Aa}$ & 98 \\
\hline & Média & 96 & 96 & 89 & \\
\hline & C.V. (\%) & & 5,8 & & \\
\hline \multirow{4}{*}{$\begin{array}{l}\text { Comprimento } \\
\text { Radicular (mm) }\end{array}$} & BRS Iraí & $129,2 \mathrm{Aa}$ & $117,0 \mathrm{Ab}$ & $95,0 \mathrm{Bc}$ & 113,7 \\
\hline & BRS Expedito & $111,5 \mathrm{Ba}$ & $114,0 \mathrm{Aa}$ & $108,2 \mathrm{Aa}$ & 111,2 \\
\hline & Média & 120,3 & 115,5 & 101,6 & \\
\hline & C.V. (\%) & & 7,3 & & \\
\hline \multirow{4}{*}{$\begin{array}{l}\text { Massa de Mil } \\
\text { Sementes (g) }\end{array}$} & BRS Iraí & 302,674 & 287,479 & 276,702 & $288,952 \mathrm{~A}$ \\
\hline & BRS Expedito & 238,9 & 225,529 & 220,223 & $228,217 \mathrm{~B}$ \\
\hline & Média & $270,787 \mathrm{a}$ & $256,504 \mathrm{~b}$ & $248,4625 \mathrm{c}$ & \\
\hline & C.V. (\%) & & 1,5 & & \\
\hline
\end{tabular}

Médias seguidas pela mesma letra, maiúscula na coluna e minúscula na linha, não diferem pelo teste de Tukey a $5 \%$ de probabilidade. 
Para a variável comprimento radicular, verificou-se interação entre os fatores estudados. A cultivar Iraí apresentou um maior comprimento radicular na maturação de colheita com 129,2 $\mathrm{mm}$, porém esses valores diminuíram para 95,0 mm à medida que houve atraso na colheita em 14 dias. Já a BRS Expedito, mesmo apresentando um comprimento radicular menor que a cultivar Iraí, conseguiu manter-se até 14 dias de atraso na colheita sem diminuir significativamente o comprimento radicular.

Não houve interação entre os fatores avaliados para a variável massa de mil sementes (Tabela 1). Houve diminuição da massa de mil sementes das cultivares Iraí e BRS Expedito à medida em que houve atrasos na colheita, provavelmente devido a processos de deterioração que ocorrem após a maturidade fisiológica. A cultivar Irai teve desempenho superior a BRS Expedito devido ao maior tamanho da semente. De acordo com os descritores, a massa média de mil sementes do cultivar Iraí é 384g CEPEF (2000), enquanto a BRS Expedito apresenta 250g (CTSBF, 2012).

TABELA 2. Valores médios de Índice de velocidade de emergência (IVE) e emergência a campo (EC) de sementes de feijão colhidas em três épocas de colheitas.

\begin{tabular}{|c|c|c|c|c|c|}
\hline \multirow{2}{*}{$\begin{array}{l}\text { Variável } \\
\text { Resposta }\end{array}$} & \multirow{2}{*}{ Genótipo } & \multicolumn{3}{|c|}{ Época de Colheita } & \multirow{2}{*}{ Média } \\
\hline & & M.C & M.C. + 7 dias & M.C. + 14 dias & \\
\hline \multirow{4}{*}{ IVE } & BRS Iraí & $12 \mathrm{Ba}$ & $14 \mathrm{Ba}$ & $11 \mathrm{Bb}$ & 12,3 \\
\hline & BRS Expedito & $16 \mathrm{Aa}$ & $15 \mathrm{Aa}$ & $15 \mathrm{Aa}$ & 15,3 \\
\hline & Média & 14 & 14,5 & 13 & \\
\hline & C.V. (\%) & & 4,94 & & \\
\hline \multirow{4}{*}{$\begin{array}{c}\text { Emergência a } \\
\text { campo (\%) }\end{array}$} & BRS Iraí & $98 \mathrm{Aa}$ & $100 \mathrm{Aa}$ & $92 \mathrm{Ab}$ & 97 \\
\hline & BRS Expedito & $94 \mathrm{Ba}$ & $96 \mathrm{Ba}$ & $94 \mathrm{Aa}$ & 95 \\
\hline & Média & 96 & 98 & 93 & \\
\hline & C.V. (\%) & & 2,38 & & \\
\hline
\end{tabular}

Médias seguidas pela mesma letra, maiúscula na coluna e minúscula na linha, não diferem pelo teste de Tukey a $5 \%$ de probabilidade.

Para a variável índice de velocidade de emergência (Tabela 2), verificou-se interação entre os fatores estudados (genótipos e épocas de colheita. A cultivar BRS Expedito apresentou maior IVE quando comparada a cultivar Iraí, mantendo um bom desempenho em todas as épocas de colheitas avaliadas. Estes resultados com o teste de germinação, em que esse mesmo genótipo conseguiu manter o percentual de germinação ao longo das diferentes épocas de colheitas.

Avaliando os dados da emergência a campo, pode-se observar que a cultivar Iraí apresentou maior percentual de emergência na maturação de colheita $98 \%$, porém esses valores diminuíram após 14 dias de atraso da colheita, atingindo o percentual de $92 \%$, evidenciando a maior susceptibilidade deste genótipo ao retardamento de colheita. Já a BRS Expedito, apresentou percentual de emergência de $94 \%$, sendo este inferior a cultivar Iraí na maturação de colheita, porém, conseguiu manter potencial até 14 dias de atraso da colheita sem diminuir o percentual de emergência, mostrando que nem sempre as cultivares com melhor qualidade fisiológica na maturação de colheita apresentam maior tolerância á deterioração á medida que se retarda a colheita (BRACCINI et al., 2003). 
O retardamento de colheita de sementes de feijão até 14 dias após a maturidade de colheita promove perdas de qualidade fisiológica de sementes, entretanto as sementes poderiam ser comercializadas tendo em vista que apresentaram germinação igual ou superior a $80 \%$ em todas as situações de colheitas estudadas.

\section{CONCLUSÕES}

O retardamento de colheita de sementes de feijão até 14 dias após a maturidade de colheita promove perdas de qualidade fisiológica de sementes, entretanto as sementes poderiam ser comercializadas tendo em vista que apresentaram germinação igual ou superior a $80 \%$ em todas as situações de colheitas estudadas.

Cultivares de feijão apresentam distintas tolerâncias à deterioração de sementes em campo devido ao retardamento de colheita.

\section{REFERÊNCIAS}

ABRASEM. Anuário Associação Brasileira Produtores de Sementes, Brasília, DF, Anuário 2014. 100 p. Disponível em: http://www.abrasem.com.br/wpcontent/uploads/2013/09/Anu\%C3\%A1rio-Abrasem-2014.pdf

ANDRADE, M. J. B.; OlIVEIRA, J. A.; ANDRADE, C. A. B.; ANDRADE, W. E. B.; FRAGA, A. C.; KIKUTI, H. Comunicação, época de colheita em cinco cultivares de feijoeiro. II. Efeitos sobre a qualidade da semente. Ciência e Agrotecnologia, v. 25, n. 3, p. 683-689, 2001.

BOTELHO, F. J. E.; GUIMARÃES, R. M.; OLIVEIRA, J. A.; EVANGELISTA, J. R. E.; ELOI, T. A.; BALIZA, D. P. Desempenho fisiológico de sementes de feijão colhidas em diferentes períodos do desenvolvimento. Ciência e Agrotecnologia, v. 34 n. 4 p. 900-907, 2010. Disponível em:

<http://www.scielo.br/scielo.php?script=sci_arttext\&pid=S141370542010000400015> . doi: 10.1590/S1413-70542010000400015

BRACCINI, A. L.; ALBRECHT, L. P.; ÁVILA, M. R.; SCAPIM, C. A.; BIO, F. E. I.; PERIGRINELLO, S. R. Qualidade fisiológica e sanitária das sementes de quinze cultivares de soja (Glycinemax (L.) Merrill) colhidas na época normal e após retardamento de colheita. Acta ScientiarumAgronomy, v. 25, n. 2, p. 449-457, $2003 . \quad$ Disponível em: <http://periodicos.uem.br/ojs/index.php/ActaSciAgron/article/view/2153/1611>. doi: 10.4025/actasciagron.v25i2.2153

BRASIL, Ministério da Agricultura, Pecuária e Abastecimento. Regras para análises de semente / Ministério de Agricultura, Pecuária e Abastecimento. Secretaria de Defesa Agropecuária. Brasília: MAPA/ACS, 2009. 399p. Disponível em:

http://www.agricultura.gov.br/arq_editor/file/2946_regras_analise_sementes.p

CANTARELLI, L. D.; SCHUCH, L. O. B.; RUFINO, C. A.; TAVARES, L. C.; VIEIRA, J. F. Physiological seeds quality: spatial distribution and variability among soybean plant population. Bioscience Journal, v. 31, n. 2, p. 344-351, 2015 a. 
Disponível

em:

<http://www.seer.ufu.br/index.php/biosciencejournal/article/view/22274>

doi: $10.14393 / B J-v 31$ 2a2015-22274

CANTARELLI, L. D.; SCHUCH, L. O. B.; TAVARES, L. C.; RUFINO, C. A. Variabilidade de plantas de soja originadas de sementes de diferentes níveis de qualidade fisiológica. Acta Agronómica, v. 64, n.3, p. 234-238, 2015b. Disponível em: <http://dx.doi.org/10.15446/acag.v64n3.45511>. DOI: 10.15446/acag.v64n3.45511

CARVALHO, J. J.; SAAD, J. C. C.; BASTOS, A. V. S.; NAVES, S. S.; SOARES, A. L.; VIDAL, V. M. Teor e acúmulo de nutrientes em grãos de feijão comum em semeadura direta, sob déficit hídrico. Irriga, Edição Especial, n. 1, p. 104-117, 2014.

CEPEF- Comissão Estadual de Pesquisa de Feijão. Recomendações técnicas para cultivo no Rio Grande do Sul. Santa Maria: UFSM, 2000. 80 p.

COMISSÃO TÉCNICA SUL-BRASILEIRA DE FEIJÃO. Informações técnicas para o cultivo de feijão na Região Sul brasileira 2012. Florianópolis: EPAGRI, 2012. $157 p$.

CONAB - Companhia Nacional de Abastecimento. Acompanhamento safra brasileira de grãos, v. 3 - Safra 2015/16, n. 6 - Sexto Levantamento, mar. 2016.

EMBRAPA. Sistema brasileiro de classificação de solos. 2. ed. Rio de Janeiro: EMBRAPA/CNPS, 2006. 306p.

GARCIA, D. C.; BARROS, A. C. S.A.; PESKE, S. T.; MENEZES, N. L. A secagem de sementes. Ciência Rural, v. 34, n. 2, p. 603-608, 2004. Disponível em:

KAPPES, C.; ARF, O.; FERREIRA, J. P.; PORTUGAL, J. R.; ALCALDE, A. M.; ARF, M. V.; VILELA, R. G. Qualidade fisiológica de sementes e crescimento de plântulas de feijoeiro, em função de aplicações de paraquat em pré-colheita. Pesquisa Agropecuária Tropical, v. 42, n. 1, p. 9-18, 2012. Disponível em:< http://dx.doi.org/10.1590/S1983-40632012000100002>. doi: 10.1590/S198340632012000100002

KOLCHINSKI, E.M.; SCHUCH, L.O.B; PESKE, S.T. Crescimento inicial de soja em função do vigor das sementes. Revista Brasileira de Agrociência, v.12, n. 2, p. 163-166, 2006.

LIMA, W. A. A.; BORÉM, A.; DIAS, D. C. F. S.; MOREIRA, M. A.; DIAS, L. A. S.; PIOVESAN, N. D. Retardamento de colheita como método de diferenciação de genótipos de soja para qualidade de sementes. Revista Brasileira de Sementes, v. 29, n. 1, p.186-192, 2007. Disponível em: <http://www.scielo.br/scielo.php? script=sci_arttext\&pid=S0101-31222007000100026>. doi: 10.1590/S01013 1222007000100026

MAMBRIN, R. B.; RIBEIRO, N. D.; HENNING, L. M. M.; HENNING, F. A.; BARKERT, $\mathrm{K}$,. A. Seleção de linhagens de feijão com base no padrão e na qualidade de 
sementes. Revista Caatinga, v. 28, n.3, p. 147-156, 2015. Disponível em: <http://www.scielo.br/pdf/rcaat/v28n3/1983-2125-rcaat-28-03-00147.pdf>. doi:

10.1590/1983-21252015v28n317rc

MARCANDALLI, L. H.; LAZARINI, E.; MALASPINA, I. G. Épocas de aplicação de dessecantes na cultura da soja: Qualidade fisiológica de sementes. Revista Brasileira de Sementes, v. 33, n. 2, p. 241-250, 2011. Disponível em: <http://www.scielo.br/scielo.php?script=sci_arttext\&pid=S0101-

31222011000200006>. doi: 10.1590/S0101-31222011000200006

MARCOS FILHO, J. Fisiologia de sementes de plantas cultivadas. Londrina-PR: 2. Ed., 2015. 600p.

MARCOS FILHO, J. Teste de envelhecimento acelerado. In: KRZYZANOWSKI, F.C.; VIEIRA, R.D.; FRANÇA NETO, J.B. (Ed.). Vigor de sementes: conceitos e testes. Londrina: ABRATES, 1999. cap.3.1, p.3.24.

MATTIONI, F.; ALBUQUERQUE, M. C. F.; MARCOS-FILHO, J.; GUIMARÃES, S. C. Vigor de sementes e desempenho agronômico de plantas de algodão. Revista Brasileira de Sementes, v. 34, n. 1, p. 108-116, 2012.

MENTEN, J. O. M.; MORAES, M. H. D.; NOVEMBRE, A. D. L. C.; ITO, M. A. Qualidade das sementes de feijão no Brasil. Pesquisa e Tecnologia, v.3, n.2, 2006.

PESKE. S T. Colheita: quando e como? Seeds News, Pelotas, v.18, n.5,p.2834,2014 .

PESKE, S. T,; BARROS, A. C.S. A.; SCHUCH, L. O. B. Produção de Sementes. In: PESKE, S. T.; VILLELA, F. A.; MENEGHELLO, G.E. Sementes: fundamentos científicos e tecnológicos. $3^{\underline{a}}$ ed. Ed. Universitária UFPel, 2012. Pelotas. 573p.

PEREIRA, V. G. C.; GRIS, D. J.; MARAGONI, T.; FRIGO, J. P.; AZEVEDO, K. D.; GRZESIUCK, A. E. Exigências Agroclimáticas para a Cultura do Feijão (Phaseolus vulgaris L.). Revista Brasileira de Energias Renováveis, v. 3, n.1, p. 32-42, 2014.

TAVARES, L.C.; RUFINO, C.A.; BRUNES, A.P.; TUNES, L.M.; BARROS, A.C.S.A.; PESKE, S.T. Desempenho de sementes de soja sob deficiência hídrica: rendimento e qualidade fisiológica da geração F1. Ciência Rural. v. 43, n. 8, p. 1357-1363, 2013. Disponível em: <http://www.scielo.br/pdf/cr/v43n8/a22213cr2012-0950.pdf>. doi: 10.1590/S0103-84782013000800003 